\title{
Carbon isotopic signatures of super-deep diamonds mediated by iron redox chemistry
}

\author{
J. Liu ${ }^{\text {* }}$, W. Wang ${ }^{2 *}$, H. Yang ${ }^{3}$, Z. Wu W,4* M.Y. Hu $^{5}$, J. Zhao ${ }^{5}$,

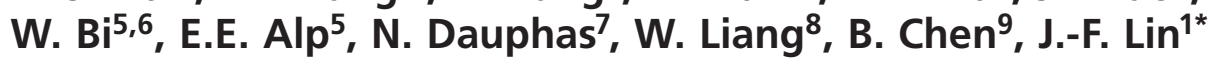

Abstract

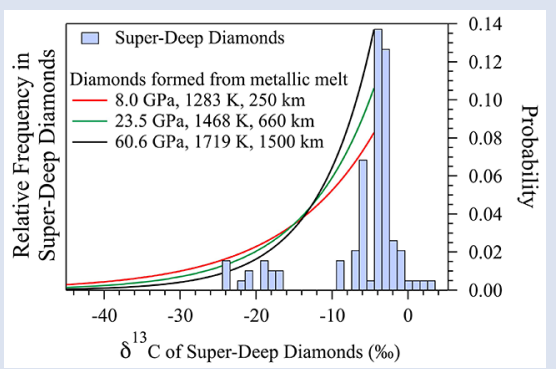

Among redox sensitive elements, carbon is particularly important because it may have been a driver rather than a passive recorder of Earth's redox evolution. The extent to which the isotopic composition of carbon records the redox processes that shaped the Earth is still debated. In particular, the highly reduced deep mantle may be metal-saturated, however, it is still unclear how the presence of metallic phases influences the carbon isotopic compositions of super-deep diamonds. Here we report $a b$ initio results for the vibrational properties of carbon in carbonates, diamond, and $\mathrm{Fe}_{3} \mathrm{C}$ under pressure and temperature conditions relevant to super-deep diamond formation. Previous work on this question neglected the effect of pressure on the equilibrium carbon isotopic fractionation between diamond and $\mathrm{Fe}_{3} \mathrm{C}$ but our calculations show that this assumption overestimates the fractionation by a factor of $\sim 1.3$. Our calculated probability density functions for the carbon isotopic compositions of super-deep diamonds derived from metallic melt can readily explain the very light carbon isotopic compositions observed in some super-deep diamonds. Our results therefore support the view that metallic phases are present during the formation of super-deep diamonds in the mantle below $\sim 250 \mathrm{~km}$.

Received 28 May 2018 | Accepted 9 April 2019 | Published 24 May 2019

\section{Introduction}

Diamonds are prime recorders of the carbon isotopic compositions of the Earth because some of them are sourced deeply from the longest, isolated regions of Earth's mantle (Cartigny et al., 2014). The $\delta^{13} \mathrm{C}$ values (deviations in per mille of ${ }^{13} \mathrm{C} /{ }^{12} \mathrm{C}$ ratios relative to $\mathrm{V}-\mathrm{PDB}$ ) of natural diamonds show a broad range of variations from $-41 \%$ to $+3 \%$ with a mode at -5 $\pm 3 \%$ o (Cartigny et al., 2014). Of particular interests are very low $\delta^{13} \mathrm{C}$ values of $-26 \%$ to $-41 \%$ found in some eclogitic and super-deep diamonds (e.g., De Stefano et al., 2009; Smart et al., 2011; Smith et al., 2016). These low $\delta^{13} \mathrm{C}$ values are most commonly found in eclogitic diamonds (e.g., Walter et al., 2011), which presumably incorporated a recycled oceanic crust component. It is thus unlikely that these $\delta^{13} \mathrm{C}$ values were inherited from Earth's primordial materials. Although eclogitic diamonds with lowest $\delta^{13} \mathrm{C}$ values may originate from organic matter at $2.0-2.7 \mathrm{Ga}\left(\delta^{13} \mathrm{C}-40 \%\right.$ o to $-60 \%$ o (Smart et al., 2011), such organic matter unlikely survives at the depths (300-1000 km) where super-deep diamonds form (e.g., Anzolini et al., 2019). Isotopic fractionation associated with diamond precipitation from either $\mathrm{CH}_{4}$ or $\mathrm{CO}_{2}$-bearing fluids (Galimov, 1991) is also an unlikely explanation for the most negative $\delta^{13} \mathrm{C}$ values measured in these diamonds. The reasons are that: (1) the equilibrium fractionation between diamond and $\mathrm{CH}_{4}$ at mantle temperatures $(\sim+1 \%$ o) is too low to drive the residual fluid to very negative $\delta^{13} \mathrm{C}$ values by Rayleigh distillation; (2) the fractionation between diamond and $\mathrm{CO}_{2}$ of $\sim-3 \%$ at mantle temperatures could only produce diamonds whose $\delta^{13} \mathrm{C}$ values are $\sim-8 \%$ or higher. Overall, the question of how some super-deep diamonds acquired highly negative $\delta^{13} \mathrm{C}$ values is still open.

1. Department of Geological Sciences, Jackson School of Geosciences, University of Texas at Austin, Austin, Texas 78712, USA

2. Laboratory of Seismology and Physics of Earth's Interior, School of Earth and Space Sciences, University of Science and Technology of China, Hefei, China

3. Center for High Pressure Science and Technology Advanced Research (HPSTAR), Pudong, Shanghai 201203, China

4. CAS Center for Excellence in Comparative Planetology, China

5. Advanced Photon Source, Argonne National Laboratory, Argonne, Illinois 60439, USA

. Department of Geology, University of Illinois at Urbana-Champaign, Urbana, Illinois 61801, USA

7. Origins Laboratory, Department of the Geophysical Sciences and Enrico Fermi Institute, The University of Chicago, 5734 South Ellis Avenue, Chicago, Illinois 60637 , USA

8. Key Laboratory for High Temperature and High Pressure Study of the Earth's Interior, Institute of Geochemistry, Chinese Academy of Sciences, Guiyang, Guizhou 550002 , China

9. Hawaii Institute of Geophysics and Planetology, University of Hawaii at Manoa, Honolulu, HI 96822, USA Corresponding author (email: jiacliu@utexas.edu; afu@jsg.utexas.edu; wuzq10@ustc.edu.cn; wz30304@mail.ustc.edu.cn) 
Through plate tectonics, relatively oxidised iron and carbon species at the Earth's surface are transported to the deep mantle by subducted slabs, where $\mathrm{Fe}^{2+}$ can disproportionate into $\mathrm{Fe}^{3+}$ and metallic Fe (Equation 1) below $250 \mathrm{~km}$ due to stabilisation of $\mathrm{Fe}^{3+}$ in garnet, pyroxene and bridgmanite (Frost et al., 2004; Rohrbach et al., 2007):

$$
3 \mathrm{FeO}=\mathrm{Fe}+\mathrm{Fe}_{2} \mathrm{O}_{3}
$$

The resulting metallic Fe would react with carbonates to form either diamond (Equation 2) or iron carbide (Equation 3), depending on the local Fe:C ratio and thus redox state (Palyanov et al., 2013):

$$
\begin{gathered}
\mathrm{FeCO}_{3}+2 \mathrm{Fe}=3 \mathrm{FeO}+\mathrm{C} \\
\mathrm{FeCO}_{3}+5 \mathrm{Fe}=3 \mathrm{FeO}+\mathrm{Fe}_{3} \mathrm{C}
\end{gathered}
$$

$\mathrm{Fe}_{3} \mathrm{C}$ can also serve as a reduced $\mathrm{C}$ source to form diamonds through the following redox reaction (Bataleva et al., 2016):

$$
\mathrm{Fe}_{3} \mathrm{C}+3 \mathrm{Fe}_{2} \mathrm{O}_{3}=9 \mathrm{FeO}+\mathrm{C}
$$

Moreover, $\mathrm{Fe}-\mathrm{C}$ alloys/mixtures may melt under the pressure and temperature $(P-T)$ conditions of the mantle because of their relatively low melting temperatures, especially in the presence of $\mathrm{Ni}$, as compared to other mantle minerals (e.g. Rohrbach et al., 2014; Liu et al., 2016). The resultant Fe-C melt can form diamonds through the reaction mediated by iron redox chemistry:

$$
\mathrm{Fe}-\mathrm{C} \text { melt }+\mathrm{Fe}_{2} \mathrm{O}_{3}=3 \mathrm{FeO}+\mathrm{C}
$$

The presence of $\mathrm{S}$ or other light elements can significantly lower $\mathrm{C}$ solubility in metallic melt and therefore promote diamond formation (Bataleva et al., 2015). For example, Fe-Ni-S-C inclusions have been found in super-deep diamonds (e.g., Kaminsky and Wirth, 2011; Smith et al., 2016). Finding such metallic inclusions requires careful examination as these inclusions are small in size ( $\mu \mathrm{m}$ to $\mathrm{nm}$ scale) and can be mistaken for graphite (Kaminsky and Wirth, 2011; Smith et al., 2016). The presence of metallic inclusions supports the view that C-bearing metallic melt could serve as a carbon source for some super-deep diamonds below $\sim 250 \mathrm{~km}$.

Horita and Polyakov (2015) have attempted to address the aforementioned question through calculations of the reduced partition function ratio ( $\beta$-factor) of $\mathrm{C}$ in $\mathrm{Fe}_{3} \mathrm{C}$ using the heat capacity and the iron phonon density of states (PDOS) at 1 bar. They combined this $\beta$-factor with previously published $\beta$-factors of diamond and carbonates to calculate the carbon equilibrium isotopic fractionation $\Delta^{13} \mathrm{C}$ between these phases,

$$
\Delta^{13} \mathrm{C}^{\mathrm{B}-\mathrm{A}}=1000\left(\ln \beta_{\mathrm{B}}-\ln \beta_{\mathrm{A}}\right)
$$

Eq. 6

where $\mathrm{A}$ and $\mathrm{B}$ are two phases in isotopic equilibrium. An important assumption that Horita and Polyakov (2015) made is that pressure has no effect on this fractionation. However, super-deep diamonds form under high P-T conditions in the mantle below $250 \mathrm{~km}$ depth, and applied pressure has undoubtedly been shown to stiffen lattice bonds and induce structural and electronic transitions, which in turn can affect $\beta$-factors of $C$ in host phases (e.g., Lin et al., 2004, 2012). In order to constrain reliably the extent of $\mathrm{C}$ isotopic fractionation during super-deep diamond formation, we used DFT augmented by a Hubbard $U$ correction method (Giannozzi et al., 2009) to calculate the $\beta$-factors of $\mathrm{C}$ in $\mathrm{MgCO}_{3}, \mathrm{FeCO}_{3}$, $\mathrm{Fe}_{3} \mathrm{C}$ and diamond (Tables S-1, S-2) at the P-T conditions of subducted slabs in the mantle. We also measured the PDOS of $\mathrm{Fe}^{2+}$ in $\mathrm{FeCO}_{3}$ by nuclear resonant inelastic $\mathrm{X}$-ray scattering (NRIXS) spectroscopy (Dauphas et al., 2018) to evaluate the accuracy of the theoretical calculations.

\section{PDOS of Fe and C in Minerals Relevant to Diamond Formation}

The DFT + Ucalculation was verified by comparing the theoretical PDOS of $\mathrm{Fe}^{2+}$ in $\mathrm{FeCO}_{3}$ with the one measured by NRIXS (Fig .1). The PDOS results in theory and experiment match well with each other, which could also support the validity of the calculated $\beta$-factors of $\mathrm{C}$ in carbonates, diamond and nonmagnetic $\mathrm{Fe}_{3} \mathrm{C}$ (Fig. S-1). Synchrotron Mössbauer spectra (Fig. S-2) and optical images (Fig. S-3) show that the spin transition of $\mathrm{Fe}^{2+}$ in $\mathrm{FeCO}_{3}$ occurs between 44-46 GPa at 300 $\mathrm{K}$. Across the spin transition, the unit cell volume collapses by $9.4 \%$, the Fe-O bond length is shortened by $4.8 \%$ (Fig. $\mathrm{S}-4)$. Meanwhile, the spin transition of iron results in $\sim 5 \%$ decrease of the $\beta$-factor of $\mathrm{C}$ in $\mathrm{LS} \mathrm{FeCO}_{3}$ compared to its $\mathrm{HS}$ state (Fig. S-5) as the C-O bound length is lengthened by 2.1 $\%$ (Fig. S-4). The magnetic state of $\mathrm{Fe}_{3} \mathrm{C}$ changes from ferromagnetic at ambient condition to paramagnetic and finally nonmagnetic at pressures higher than $22-60 \mathrm{GPa}$ (Lin et al., 2004; Gao et al., 2008). Therefore, nonmagnetic $\mathrm{Fe}_{3} \mathrm{C}$ is the relevant phase for most mantle depths. Similar to previous theoretical calculations (Horita and Polyakov, 2015) and C isotopic measurements on natural diamonds and iron carbide inclusions (Mikhail et al., 2014), the magnitude of $\Delta C^{\text {Dia-Fe } 3} \mathrm{C}$ is larger than other inter-mineral fractionations involving diamond, such as $\Delta C^{\text {Dia-Carbonates }}$ (Fig. S-6). Our calculated $\Delta \mathrm{C}^{\mathrm{Dia}-\mathrm{Fe}_{3} \mathrm{C}}$ values along the representative $P-T$ conditions of modern mantle and cold slab (Fig. S-6) are as much as $27 \%$ lower than the 1-bar value of $\Delta \mathrm{C}^{\mathrm{Dia}-\mathrm{Fe}_{3} \mathrm{C}}$ reported by Horita and Polyakov (2015). Therefore the 1-bar data would overestimate the $\mathrm{C}$ isotopic fractionation during diamond formation from a $\mathrm{Fe}_{3} \mathrm{C}$ source under mantle $P$ - $T$ conditions.

\section{Carbon Isotopic Fractionation in Diamonds through Redox Reactions}

As discussed by Horita and Polyakov (2015), the most significant reaction that can impart $C$ isotopic fractionation to diamonds is one involving the oxidation of $\mathrm{C}$ alloyed with metallic melt to release $\mathrm{C}$ to form diamonds (Equation 5). To assess how redox reactions involving Fe-C melt below $\sim 250 \mathrm{~km}$ can influence the $\delta^{13} \mathrm{C}$ values of super-deep diamonds, we modelled the isotopic fractionation of $\mathrm{C}$ between diamond and Fe-C melt. Our calculations accounting for various $P-T$ and compositional factors allow us to test whether this diamond formation pathway can account for their $\delta^{13} \mathrm{C}$ values.

The $\mathrm{C}$ isotopic fractionation can be modelled by using a Rayleigh distillation if the diamonds produced do not backreact with the $\mathrm{C}$ source, which is reasonable if the $\mathrm{Fe}-\mathrm{C}$ source is a melt and the reaction product is a solid characterised by a low self-diffusivity (Koga et al., 2005). As it is challenging to calculate the $\beta$-factor of $\mathrm{C}$ in Fe-C melt directly, $\Delta^{13} \mathrm{C}^{\mathrm{Dia}-\mathrm{FeC} \text { melt }}$ is calculated by the sum of $\Delta^{13} C^{\text {Dia-Fe }}{ }_{3} \mathrm{C}$ (Fig. S-6) and the equilibrium fractionation $\Delta^{13} \mathrm{C}^{\mathrm{Fe}_{3} \mathrm{C}-\mathrm{FeC} \text { melt }}=-5.6 \times 10^{6} / \mathrm{T}^{2}$ anchored to the experimentally determined value of $\sim-2 \%$ at $6.3 \mathrm{GPa}$ and $1673 \mathrm{~K}$ (Reutsky et al., 2015). By using this calculated $\Delta^{13} \mathrm{C}^{\mathrm{Dia}-\mathrm{FeC} \text { melt }}, \delta^{13} \mathrm{C}$ values of diamonds forming from metallic melt can be calculated using a Rayleigh distillation model. Relative to the $\mathrm{Fe}-\mathrm{C}$ melt source, the diamonds are enriched in the heavy isotope of $\mathrm{C}$. Removal of isotopically heavy diamonds would have driven the $\mathrm{Fe}-\mathrm{C}$ melt reservoir towards lower $\delta^{13} \mathrm{C}$ values and diamonds formed from this low $\delta^{13} \mathrm{C}$ reservoir progressively acquired more negative $\delta^{13} \mathrm{C}$ values. 
$\mathrm{Fe}$
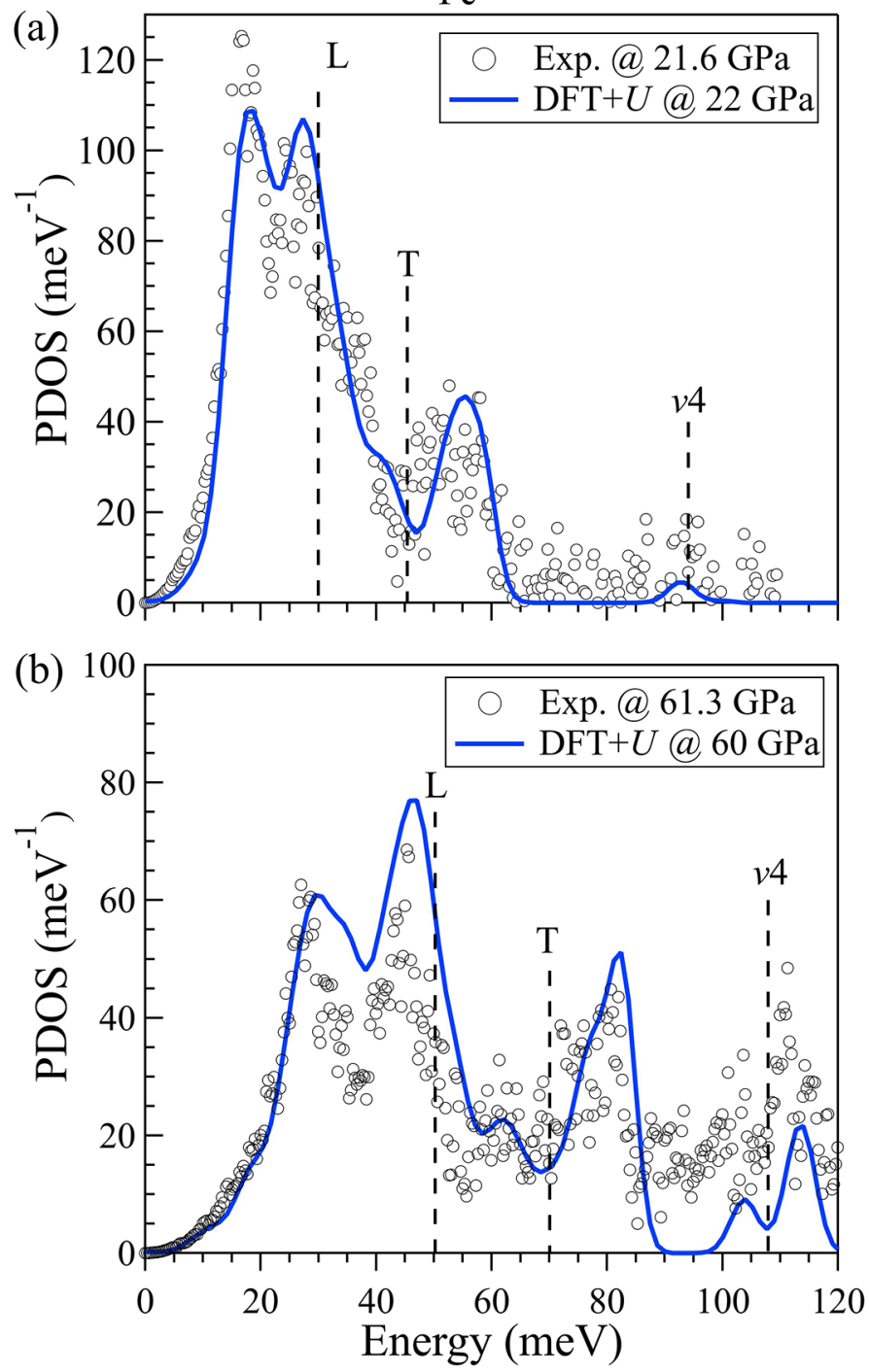

(c)

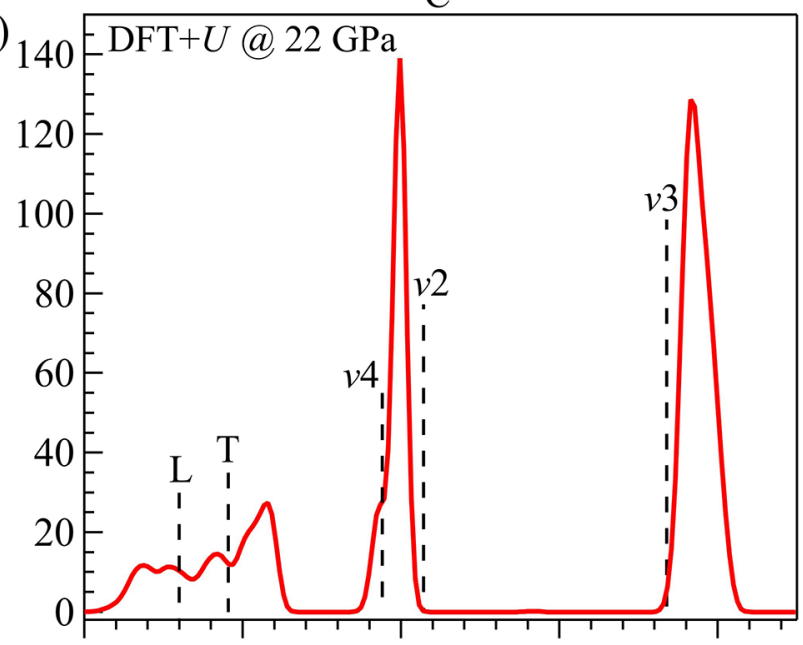

(d)

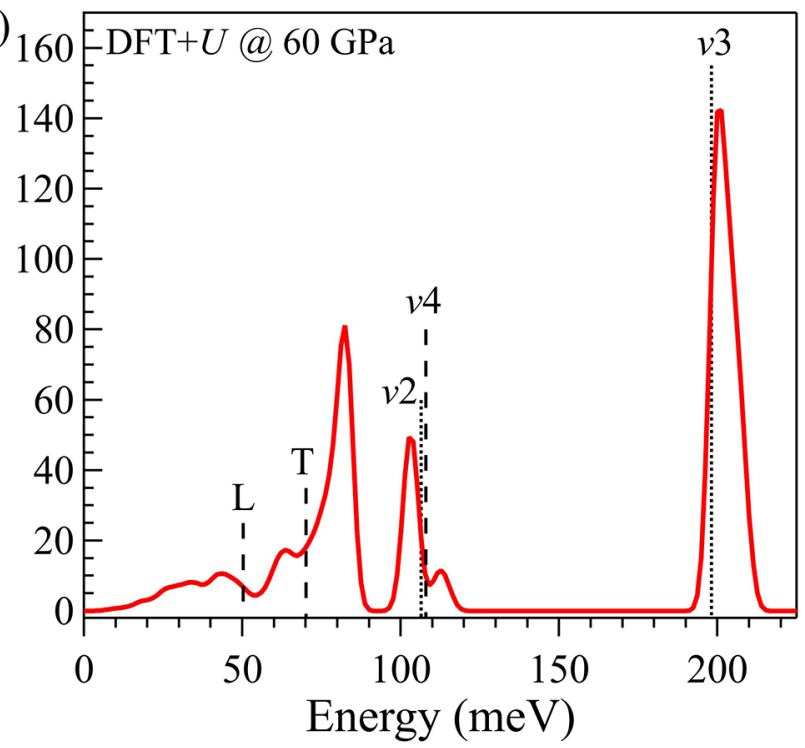

Figure 1 Partial phonon density of states (PDOS) of ${ }^{57} \mathrm{Fe}(\mathbf{a}, \mathbf{b})$ and ${ }^{12} \mathrm{C}(\mathbf{c}, \mathbf{d})$ in $\mathrm{FeCO}_{3}$ at high pressures. In (a) and (b), the open cycles are PDOS of Fe measured by NRIXS; the blue curves are calculated PDOS of Fe by DFT + U. The red curves in (c) and (d) are calculated PDOS of $C$. The lowest energy peak at $20-40 \mathrm{meV}$ can be attributed to the acoustic phonons. According to previous high pressure Raman and infrared studies of $\mathrm{FeCO}_{3}$ (Santillán and Williams, 2004; Lin et al., 2012), the other peaks can be assigned to librational mode $(\mathrm{L})$, translational mode $(\mathrm{T})$ and in-plane bending mode $(\mathrm{v} 4)$, out of plane bending vibration $(\mathrm{v} 2)$ and asymmetric stretch ( $v 3$ ) of $\mathrm{CO}_{3}{ }^{2-}$ (marked as dashed vertical lines). The energies of $v 2$ and $v 3$ modes (marked as dotted vertical lines) at $60 \mathrm{GPa}$ are linearly extrapolated from those measured up to $50 \mathrm{GPa}$ for $\mathrm{FeCO}_{3}$ (Santillán and Williams, 2004). In the PDOS of Fe at $60 \mathrm{GPa}$ (b), the splitting of $v 4$ mode at approximately 100-120 meV has also been observed in a previous Raman study (Lin et al., 2012), which is explained as a result of the enhanced interaction between low-spin $\mathrm{Fe}^{2+}$ and neighbouring $\mathrm{CO}_{3}{ }^{2-}$ units.

The probability density function (PDF) of $\delta^{13} \mathrm{C}^{\text {Dia }}$ values of diamond formed from metallic melt, which we note as $\mathrm{g}\left(\delta^{13} \mathrm{C}^{\text {Dia }}\right)$, is simply given as below (see detailed derivation in Supplementary Information),

$g\left(\delta^{13} C^{\text {Dia }}\right)=1 / \Delta^{13} C^{\text {Dia-Source }} \exp \left[\left(\delta^{13} C^{\text {Dia }}-\delta^{13} C_{0}^{\text {Source }}\right) / \Delta^{13} C^{\text {Dia-Source }}-1\right]$

The PDFs for $\Delta^{13} \mathrm{C}^{\mathrm{Dia}-\mathrm{Fe}_{3} \mathrm{C}}$ at representative upper mantle, transition zone, and lower mantle depths are shown in Figure 2. For each PDF, $\delta^{13} \mathrm{C}_{0}$ Source is set to locate the maximum probability of $\delta^{13} \mathrm{C}^{\text {Dia }}$ at $-5 \%$, which is the mode of $\delta^{13} \mathrm{C}$ of worldwide diamonds (Cartigny et al., 2014). Because of the decrease of $\Delta^{13} \mathrm{C}^{\text {Dia-FeC melt }}$ with increasing depth and temperature, the extent of the negative tail of each PDF decreases with depth where diamonds form (Fig. 2). For example, the cumulative probability of $\delta^{13} \mathrm{C}^{\mathrm{Dia}}$ values lower than $-26 \%$ is $\sim 0.17$ at $250 \mathrm{~km}$, and it decreases to 0.10 and 0.05 at 660 and $1500 \mathrm{~km}$ depths, respectively (Fig. S-7). This shows that super-deep diamonds with very light $C$ isotope could have formed from C-bearing metallic melt in the reduced part $(>250 \mathrm{~km})$ of the upper mantle.

\section{Conclusion}

By using the $\beta$-factors of carbon in relevant minerals/melt, the carbon isotopic fractionations between carbon-bearing phases possibly involved in super-deep diamond formation are calculated. The corresponding PDFs for $\delta^{13} \mathrm{C}$ of super-deep diamonds from different carbon sources are derived. Based on the comparison between the histogram for $\delta^{13} \mathrm{C}$ of super-deep diamonds and the derived PDFs, super-deep diamonds could crystallise from C-saturated metallic melt, thus supporting the existence of a deep mantle saturated in metallic iron. 


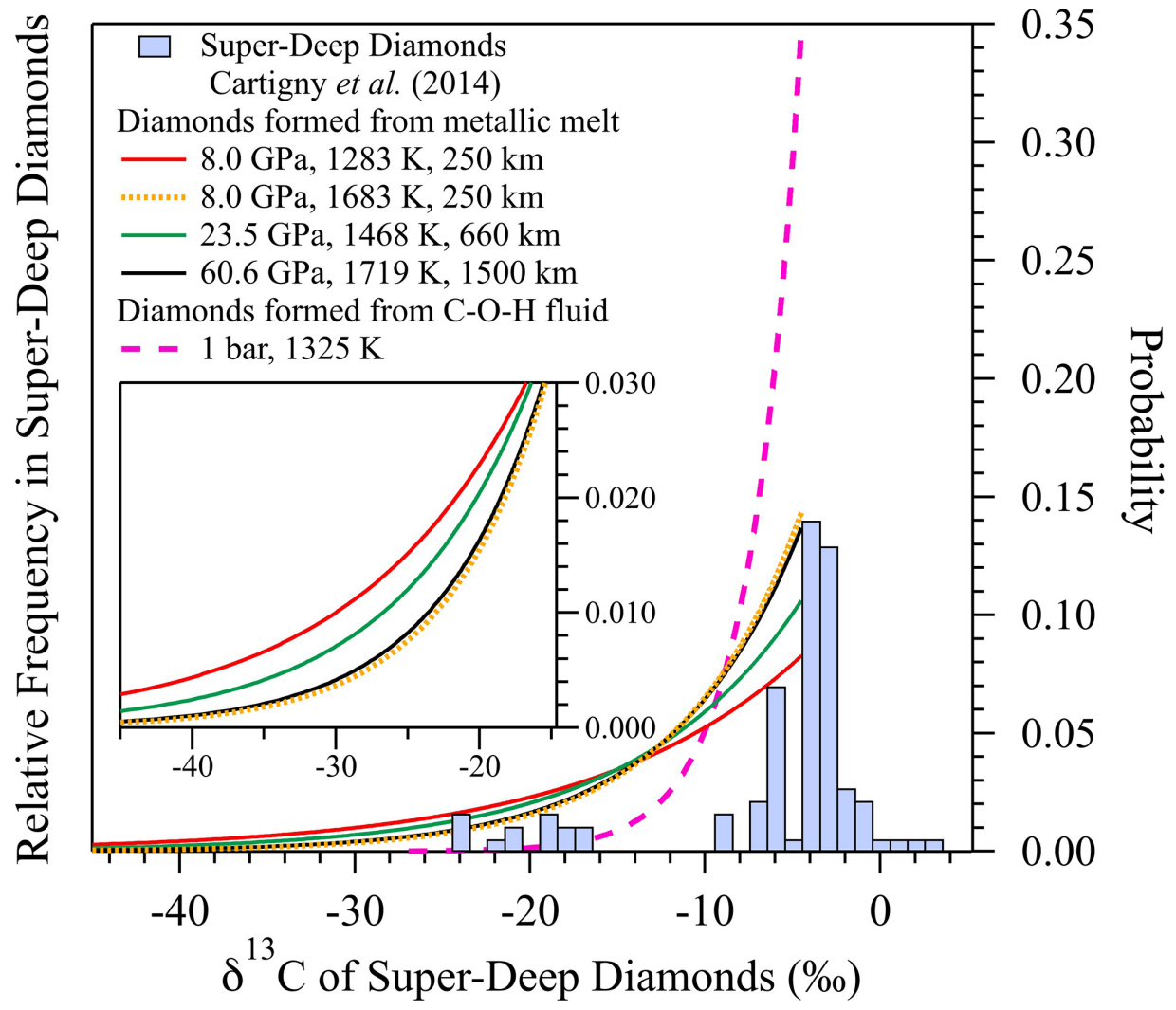

Figure 2 Comparison of the histogram for $\delta^{13} \mathrm{C}$ of super-deep diamonds (left axis) and the probability density functions (PDFs, right axis) of $\delta^{13} C^{\text {Dia }}$ derived from metallic melt for different $P-T$ conditions. The red, green and black solid curves are calculated PDFs by using $\Delta^{13} \mathrm{C}^{\mathrm{Dia}-\mathrm{FeC} \text { melt }}$ at $250 \mathrm{~km}, 660 \mathrm{~km}$ and $1500 \mathrm{~km}$ depths along a cold slab geotherm (Yang et al., 2017), respectively. The yellow dotted curve is calculated by using $\Delta^{13} \mathrm{CDia}^{\mathrm{FeC}}$ melt at $250 \mathrm{~km}$ along the modern mantle geotherm (Yang et al., 2017), which may be similar to the Archean mantle geotherm (Santosh et al., 2010). The pink dashed curve is for diamonds forming from C-H-O fluids, which is calculated using the largest reported value of $\Delta^{13} \mathrm{C}^{\mathrm{Dia}-\mathrm{COH}}(-2.9 \%)$ (Cartigny et al., 2014). The inset figure shows the negative tailings of these three PDFs. $\delta^{13} \mathrm{C}$ data of super-deep diamonds are from Cartigny et al. (2014).

\section{Acknowledgements}

W.Z. Wang and Z.Q. Wu acknowledge the Strategic Priority Research Program of the Chinese Academy of Sciences (XDB18000000), the Natural Science Foundation of China (41721002). J.F.L. and N.D. acknowledge support from CSEDI of the NSF Geophysics Program (EAR-1502594). NRIXS experiments used resources of the Advanced Photon Source, a U.S. Department of Energy (DOE) Office of Science User Facility operated for the DOE Office of Science by Argonne National Laboratory under Contract No. DE-AC02-06CH11357. W. Liang acknowledges the National Science Foundation for Young Scientists of China (41802044). W.L. Bi acknowledges COMPRES, the Consortium for Materials Properties Research in Earth Sciences under NSF Cooperative Agreement EAR 1606856. B. Chen acknowledges support from NSF grants EAR-1555388 and EAR-1565708.

Editor: Wendy Mao

\section{Author Contributions}

J.C. Liu and W.Z. Wang contributed equally to this work. J.F. Lin, J.C. Liu and W.Z. Wang designed this project; J.C. Liu, H. Yang, N. Dauphas, M.Y. Hu, J.Y. Zhao, W.L. Bi, E.E. Alp, $\mathrm{W}$. Liang and B. Chen performed the experiments and data analysis; W.Z. Wang and Z.Q. Wu performed the calculations; J.C. Liu, W.Z. Wang, N. Dauphas and J.F. Lin wrote the paper.

\section{Additional Information}

Supplementary Information accompanies this letter at http:// www.geochemicalperspectivesletters.org/article1915.

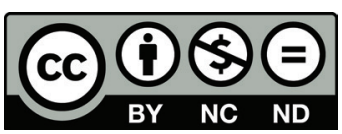

This work is distributed under the Creative Commons Attribution Non-Commercial No-Derivatives 4.0 License, which permits unrestricted distribution provided the original author and source are credited. The material may not be adapted (remixed, transformed or built upon) or used for commercial purposes without written permission from the author. Additional information is available at http://www.geochemicalperspectivesletters.org/ copyright-and-permissions.

Cite this letter as: Liu, J., Wang, W., Yang, H., Wu, Z., Hu, M.Y., Zhao, J., Bi, W., Alp, E.E., Dauphas, N., Liang, W., Chen, B., Lin, J.-F. (2019) Carbon isotopic signatures of super-deep diamonds mediated by iron redox chemistry. Geochem. Persp. Let. 10, 51-55.

\section{References}

ANZOLINI, C. ET AL. (2019) Depth of diamond formation obtained from single periclase inclusions. Geology 47, 219-222.

Bataleva, Y.V., PAlyanov, Y.N., Borzdov, Y.M., Bayukov, O.A., SoboleV, N.V. (2015) Interaction of iron carbide and sulfur under $\mathrm{P}-\mathrm{T}$ conditions of the lithospheric mantle. Doklady Earth Sciences 463, 707-711. 
Bataleva, Y.V., Palyanov, Y.N., Borzdov, Y.M., BayUKoV, O.A., SoboLEV, N.V. (2016) Conditions for diamond and graphite formation from iron carbide at the P-T parameters of lithospheric mantle. Russian Geology and Geophysics 57, 176-189.

Cartigny, P., Palot, M., Thomassot, E., Harris, J.W. (2014) Diamond Formation: A Stable Isotope Perspective. Annual Review of Earth and Planetary Sciences 42, 699-732.

Dauphas, N., Hu, M.Y., Baker, E.M., Hu, J., Tissot, F.L.H., Alp, E.E., Roskosz, M., ZhaO, J., Bi, W., LiU, J., J.-F., NieA, N.X., Heard, A. (2018) SciPhon: a data analysis software for nuclear resonant inelastic X-ray scattering with applications to $\mathrm{Fe}, \mathrm{Kr}, \mathrm{Sn}, \mathrm{Eu}$ and Dy. Journal of Synchrotron Radiation 25, 1581-1599.

De Stefano, A., Kopylova, M.G., Cartigny, P., Afanasiev, V. (2009) Diamonds and eclogites of the Jericho kimberlite (Northern Canada). Contributions to Mineralogy and Petrology 158, 295-315.

Frost, D.J., Liebske, C., Langenhorst, F., McCammon, C.A., Tronnes, R.G., RuBIE, D.C. (2004) Experimental evidence for the existence of iron-rich metal in the Earth's lower mantle. Nature 428, 409-412.

GALIMOV, E.M. (1991) Isotope fractionation related to kimberlite magmatism and diamond formation. Geochimica et Cosmochimica Acta 55, 1697-1708.

GaO, L., Chen, B., WANG, J., Alp, E.E., ZhaO, J., Lerche, M., SturhahN, W., Scott, H.P., HuAnG, F., Ding, Y., Sinogeikin, S.V., LundSTROM, C.C., BASS, J.D., LI, J. (2008) Pressure-induced magnetic transition and sound velocities of $\mathrm{Fe}_{3} \mathrm{C}$ : Implications for carbon in the Earth's inner core. Geophysical Research Letters 35, L17306.

Giannozzi, P., Baroni, S., Bonini, N., Calandra, M. , Car, R., ET $A L$. (2009) QUANTUM ESPRESSO: a modular and open-source software project for quantum simulations of materials. Journal of Physics: Condensed Matter 21, 395502

Horita, J., Polyakov, V.B. (2015) Carbon-bearing iron phases and the carbon isotope composition of the deep Earth. Proceedings of the National Academy of Sciences 112, 31-36.

KAMINSKY, F.V., WiRTH, R. (2011) Iron Carbide Inclusions in Lower-Mantle Diamond from Juina, Brazil. Canadian Mineralogist 49, 555-572.

Koga, K.T., Walter, M.J., NaKamura, E., Kobayashi, K. (2005) Carbon self-diffusion in a natural diamond. Physical Review B 72, 024108.

Lin, J.-F., Struzhkin, V.V., MaO, H., Hemley, R.J., Chow, P., Hu, M.Y., LI, J. (2004) Magnetic transition in compressed $\mathrm{Fe}_{3} \mathrm{C}$ from x-ray emission spectroscopy. Physical Review B 70, 212405.

LiN, J.-F., LiU, J., JACOBS, C., PRAKAPENKA, V.B. (2012) Vibrational and elastic properties of ferromagnesite across the electronic spin-pairing transition of iron. American Mineralogist 97, 583-591.

LiU, J., Li, J., HRUBiaK, R., SMith, J.S. (2016) Origins of ultralow velocity zones through slab-derived metallic melt. Proceedings of the National Academy of Sciences 113, 5547-5551.

Mikhail, S., Guillermier, C., Franchi, I.A., Beard, A.D., Crispin, K. Verchovsky, A.B., Jones, A.P., Milledge, H.J. (2014) Empirical evidence for the fractionation of carbon isotopes between diamond and iron carbide from the Earth's mantle. Geochemistry, Geophysics, Geosystems 15, 855-866.

Palyanov, Y.N., Bataleva, Y.V., SoKol, A.G., Borzdov, Y.M., KuprIYANOV, I.N., REUTSKY, V.N., SobOLEV, N.V. (2013) Mantle-slab interaction and redox mechanism of diamond formation. Proceedings of the National Academy of Sciences of the United States of America 110, 20408-20413.

Reutsky, V.N., Borzdov, Y.M., PALyanov, Y.N. (2015) Carbon isotope fractionation during high pressure and high temperature crystallization of Fe-C melt. Chemical Geology 406, 18-24.

Rohrbach, A., Ballhaus, C., Golla-Schindler, U., Ulmer, P., KameNETSKY, V.S., KUZMIN, D.V. (2007) Metal saturation in the upper mantle. Nature 449, 456-458.

Rohrbach, A., GHosh, S., Schmidt, M.W., Wijbrans, C.H., Klemme, S (2014) The stability of Fe-Ni carbides in the Earth's mantle: Evidence for a low $\mathrm{Fe}-\mathrm{Ni}-\mathrm{C}$ melt fraction in the deep mantle. Earth and Planetary Science Letters 388, 211-221.

SANTILLÁN, J., Williams, Q. (2004) A high-pressure infrared and X-ray study of $\mathrm{FeCO}_{3}$ and $\mathrm{MnCO}_{3}$ : comparison with $\mathrm{CaMg}\left(\mathrm{CO}_{3}\right)_{2}$-dolomite. Physics of the Earth and Planetary Interiors 143-144, 291-304.

Santosh, M., Maruyama, S., KomiYA, T., Yamamoto, S. (2010) Orogens in the evolving Earth: from surface continents to 'lost continents' at the core-mantle boundary. Geological Society, London, Special Publications $338,77-116$

Smart, K.A., Chacko, T., Stachel, T., Muehlenbachs, K., Stern, R.A., HEAMAN, L.M. (2011) Diamond growth from oxidized carbon source beneath the Northern Slave Craton, Canada: $\mathrm{A} \delta^{13} \mathrm{C}-\mathrm{N}$ study of eclogite-hosted diamonds from the Jericho kimberlite. Geochimica et Cosmochimica Acta 75, 6027-6047.
Smith, E.M., Shirey, S.B., Nestola, F., Bullock, E.S., Wang, J.H., RICHARDSON, S.H., WANG, W.Y. (2016) Large gem diamonds from metallic liquid in Earth's deep mantle. Science 354, 1403-1405.

Walter, M.J., Kohn, S.C., Araujo, D., Bulanova, G.P., Smith, C.B., Gaillou, E., Wang, J., Steele, A., Shirey, S.B. (2011) Deep Mantle Cycling of Oceanic Crust: Evidence from Diamonds and Their Mineral Inclusions. Science 334, 54-57.

YANG, D., WANG, W., WU, Z. (2017) Elasticity of superhydrous phase B at the mantle temperatures and pressures: Implications for $800 \mathrm{~km}$ discontinuity and water flow into the lower mantle. Journal of Geophysical Research: Solid Earth 122, 5026-5037. 